\title{
ESTADO E MERCADO NA REFORMA AGRÁRIA BRASILEIRA (1988-2002)
}

\author{
State and market in Brazilian agrarian
}

reform (1988-2002)

\section{JOÃO MÁRCIO MENDES PEREIRA}

http://dx.doi.org/10.1590/S0103-21862015000200009

João Márcio Mendes Pereira é doutor em História pela UFF, professor adjunto do Programa de Pós-Graduação em História da UFRRJ e professor colaborador do Programa de Pós-Graduação em Desenvolvimento Territorial na América Latina e Caribe da UNESP. É bolsista Jovem Cientista do Nosso Estado da FAPERJ e coordenador do Grupo de Estudos sobre o Agro Contemporâneo (GEAC - http://r1.ufrrj.br/geac/portal/).

Artigo recebido em 10 de junho e aprovado para publicação em 13 de outubro de 2015. 


\title{
Resumo
}

0 artigo analisa a política de reforma agrária do Brasil no período de 1988 a 2002, problematizando a relação entre Estado e mercado no desenho de tal política. Aborda os marcos legais sobre o tema estabelecidos pela Constituição Federal de 1988 e a Lei Agrária de 1993, bem como a ação dos governos Collor de Mello, Itamar Franco e Fernando Henrique Cardoso. Dá destaque também à disputa política em torno da implantação da reforma agrária assistida pelo mercado, financiada pelo Banco Mundial. 0 texto se baseia em documentos do governo brasileiro, do Banco Mundial e entrevistas com atores políticos.

PalaVRAS-CHAVE: reforma agrária, movimentos sociais do campo, reforma agrária assistida pelo mercado, neoliberalismo.

\begin{abstract}
The article analyzes the policy of agrarian reform in Brazil in the period 1988-2002, discussing the relationship between state and market in its formulation. It approaches the legal milestones established by the 1988 Federal Constitution and the 1993 Agrarian Law, as well as the actions of Collor de Mello, Itamar Franco and Fernando Henrique Cardoso administrations. It also highlights the political disputes about the implementation of an agrarian reform assisted by the market, financed by the World Bank. The text is based on documents of Brazilian government and of the World Bank and on interviews with political actors.
\end{abstract}

KEYwORDs: agrarian reform, rural social movements, land reform assisted by the market, neoliberalism.

\section{RÉSUMÉ}

L'article analyse la politique de réforme agraire au Brésil aux années 1988-2002, en discutant les rapports entre l'Etat et le marché dans sa conception. On examine les exigences légales établies par la Constitution Fédérale de 1988 et la Loi Agraire de 1993, ainsi que l'action des administrations Collor de Mello, Itamar Franco et Fernando Henrique Cardoso. On souligne aussi les disputes politiques autor d'une réforme agraire appuyée par le marché, financée par la Banque Mondiale. Le texte est basé sur des documents du gouvernement brésilien, de la Banque Mondiale, et sur des interviews.

MoTS-CLÉS: réforme agraire, mouvements paysans, réforme agraire assistée par le marché, néolibéralisme. 
As reformas agrárias que lograram êxito, do ponto de vista dos pobres da zona rural, invariavelmente continham um elemento de confisco, do ponto de vista dos grandes proprietários, que perderam parte de seus direitos e privilégios. A reforma agrária é, necessariamente, um processo político. Se as relações de domínio da terra forem realmente alteradas, de modo a beneficiar os colonos, os trabalhadores sem terra ou camponeses, isto implica uma mudança nas relações de poder em favor daqueles que trabalham fisicamente na terra, às custas daqueles que primordialmente acumulam riquezas a partir de seu controle sobre a terra rural e sobre seu trabalho.

Sólon Barraclough (2001: 378-379).

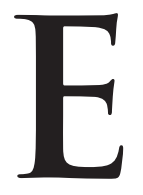

ste artigo analisa a política de reforma agrária do Brasil desde a promulgação da Constituição Federal de 1988 até o final do governo de Fernando Henrique Cardoso (FHC), problematizando a relação entre Estado e mercado no desenho de tal política. 0 trabalho está organizado em quatro partes. Inicialmente, aborda os marcos legais sobre 0 tema estabelecidos na Constituição e na Lei Agrária de 1993, bem como a ação dos governos Collor de Mello e Itamar Franco. Na sequência, argumenta como e por que a reforma agrária entrou na agenda do governo FHC. A seguir, analisa o principal item da agenda desse governo: a promoção da reforma agrária assistida pelo mercado, financiada pelo Banco Mundial (BM), contra a qual se posicionaram as principais organizações de representação de trabalhadores rurais do país. Depois, discute a política agrária do segundo governo de FHC, quando iniciativas até então relativamente dispersas foram articuladas em uma estratégia mais clara. A conclusão retoma os pontos centrais da análise. 0 trabalho se baseia em fontes documentais do governo brasileiro, do BM e em entrevistas semiestruturadas realizadas com atores políticos decisivos no processo aqui estudado.

\section{DA CONSTITUIÇÃO DE 1988 À ELEIÇÃO DE 1994}

Constituição de 1988, mediante pressão popular, alargou a esfera de direitos de ci-
dadania no Brasil, com a extensão do direito de voto aos analfabetos e a criação do Sistema Único de Saúde, entre muitas outras inovações. Porém o mesmo não ocorreu em relação à democratização do acesso à terra (Gomes da Silva, 1989 e 1996). Representou um avanço o fato de que pela primeira vez a expressão "reforma agrária" aparecesse num texto constitucional, e se definisse que a propriedade deve cumprir uma "função social", entendida como aproveitamento racional, utilização adequada dos recursos naturais e preservação do 
meio ambiente, cumprimento da legislação trabalhista e exploração que favoreça o bem-estar de trabalhadores e proprietários. Todavia, a definição dos critérios de cumprimento da função social permaneceu bastante ambígua, com exceção do que se refere à legislação trabalhista. O texto apagou qualquer referência ao "latifúndio", não estabeleceu o limite máximo de propriedade da terra, não adotou o dispositivo da perda sumária e não definiu os assentados da reforma agrária como público prioritário da política agrícola, como reivindicavam os movimentos populares do campo. Além disso, manteve no Judiciário a decisão sobre a imissão de posse para fins de desapropriação, dando margem à lentidão jurídica e ao atraso na implantação de assentamentos.

Quanto às desapropriações, a Constituição estabeleceu prévia e justa indenização em Títulos da Dívida Agrária (TDAs), resgatáveis em até 20 anos, com a garantia de preservação do valor real. Desse modo, consolidou-se a tendência de remuneração dos proprietários com base em valores de mercado, premiando, ao invés de punir, o proprietário que descumprir a função social. ${ }^{1}$ A Constituição também tornou a pequena e a média propriedades rurais não passíveis de desapropriação para fins de reforma agrária, bem como a propriedade produtiva. A regulamentação do que seria considerado "propriedade produtiva" ficou a cargo de legislação complementar, o que só ocorreria cinco anos depois.

Com a aprovação da Lei Agrária em fevereiro de 1993, os modestos dispositivos constitucionais sobre reforma agrária foram regulamentados (Ferreira et al., 2009; Medeiros, 2002). A imprecisão do termo "propriedade produtiva" foi mantida, deixando margem para que fosse interpretado juridicamente como equivalente ora a terra "fértil", ora a terra "em produção". A consequência, no primeiro caso, seria a destinação de terras inférteis (impróprias à atividade agrícola) à reforma agrária. No segundo caso, o resultado seria a proteção contra a desapropriação caso alguma parcela fosse explorada economicamente, mesmo que descumprisse outros critérios da função social (Gomes da Silva, 1996). Assim, essa imprecisão jurídica deu margem para interpretações que, desde então, valorizam o critério econômico em detrimento dos critérios ambiental e trabalhista.

Além disso, diferentemente da desapropriação por utilidade pública, em que o proprietário só pode questionar na Justiça o valor da indenização, no caso da desapropriação para fins de reforma agrária o proprietário pode questionar o mérito da ação (Gomes da Silva, 1996). Isso Ihe possibilita manejar o rito processual a seu favor e atrasar o início do processo de assentamento por tempo indeterminado, ou até reverter processos de desapropriação mesmo após a criação de assentamentos.

A legislação estabeleceu mecanismos que atribuem ao Judiciário a decisão sobre diversos pontos vitais à operacionalização da política fundiária, criando condições para a judi- 
cialização crescente da questão agrária. Isso evidenciou o fato de que a socialização jurídica predominante entre os operadores da lei no Brasil era - e ainda é - pautada por uma visão de direito de propriedade como algo inviolável e absoluto (Fachin, 1993), o que tem alimentado uma postura desfavorável aos sem terra por parte da maioria dos juízes que julgam os conflitos agrários no país.

A correlação de forças institucionalizada na Constituição de 1988 e na legislação subsequente inviabilizou a realização de uma reforma agrária estrutural e massiva no Brasil, como reivindicavam os movimentos populares do campo. 0 marco legal vigente desde então permite, no máximo, políticas de assentamentos, bastante sensíveis a variações conjunturais.

A disputa pela presidência da República em 1989 acabou polarizada entre Collor de Mello (PRN) e Lula da Silva (PT). Os movimentos populares saíram às ruas, ao mesmo tempo em que greves eclodiam por todo o país. Enquanto isso, forças empresariais e militares agitavam bandeiras como o anticomunismo, a modernização do país, o combate à corrupção e aos "privilégios" do funcionalismo público. Grandes grupos de comunicação veicularam a ideia de que o país vivia uma "guerra interna" (Dreifuss, 1989: 266-294). Ao fim e ao cabo, a derrota de Lula representou não a derrota de um partido, mas de um projeto democrático-popular alimentado por uma década de lutas sociais no campo e nas cidades (Dagnino, 2004).

Coincidentemente, com a queda do Muro de Berlim no mesmo ano, chegava ao fim a guerra fria. Na América Latina, diversos governos democraticamente eleitos se comprometiam com a aplicação do programa neoliberal sintetizado no Consenso de Washington. Era o caso de Collor de Mello. Entre outras medidas, sua gestão promoveu uma política econômica que deteriorou severamente as condições de vida e de emprego no campo e nas cidades. Em nome do combate a "privilégios" na administração pública e da modernização administrativa, avançou no desmantelamento do modelo de intervenção do Estado em vários setores, inclusive na agricultura, por meio da redução drástica do volume de recursos para a política agrícola, da liquidação da política de estoques públicos de alimentos, da abertura comercial unilateral e da extinção da Empresa Brasileira de Assistência Técnica e Extensão Rural (Ferreira et al., 2009). O Instituto Nacional de Colonização e Reforma Agrária (INCRA) permaneceu paralisado por falta de recursos.

0 tratamento dado às lutas populares se limitou à repressão e à criminalização. Além disso, esse governo não efetuou nenhuma nova desapropriação para fins de reforma agrária. Por sua vez, os assentamentos existentes foram abandonados à sua própria sorte. Ao mesmo tempo, o governo estimulou outros instrumentos de obtenção de terras segundo a lógica mercantil, como a criação de bolsas de arrendamento (Leite e Medeiros, 2004). 
Já o governo Itamar (1992-94) fez uma inflexão no tratamento dado aos movimentos sociais do campo. Pela primeira vez um presidente da República se reuniu com representantes do Movimento dos Trabalhadores Rurais Sem Terra (MST), reconhecendo a organização como interlocutor legítimo. Pessoas com trânsito e credibilidade entre movimentos sociais foram nomeadas para a direção do INCRA no início de 1993 (Stédile e Fernandes, 1999; Medeiros, 2002). Além disso, com a aprovação da Lei Agrária em maio do mesmo ano, os modestos dispositivos constitucionais sobre reforma agrária foram regulamentados, viabilizando a realização de desapropriações. 0 tema voltou a ter algum espaço na agenda governamental, tanto pela pressão de movimentos sociais como pela sua associação com o combate à fome. ${ }^{2}$ Porém, com a implantação do programa de estabilização monetária (Plano Real), pressões políticas variadas dentro e fora do governo minaram a execução do limitado programa de assentamentos.

A disputa presidencial de 1994 foi polarizada entre Luís Inácio Lula da Silva (PT) e Fernando Henrique Cardoso (PSDB) em torno da política macroeconômica e do combate à inflação. 0 tema da reforma agrária apareceu discretamente e ambos os candidatos se posicionaram a favor da medida, mas com propostas distintas (Carvalho Filho, 2001). 0 programa do PT considerava-a uma política de caráter estrutural e propunha 0 assentamento de 800 mil famílias sem terra. A desapropriação figurava como o principal instrumento de redistribuição de terras. Já o programa do PSDB prometia assentar 280 mil famílias, sem qualquer pretensão de mudança estrutural, tratando o assunto como medida de alívio da pobreza rural.

\section{O INÍCIO DO GOVERNO FHC (1995-1997)}

Arente de um projeto radical de transnacionalização da economia brasileira, o governo ção de taxas de juros elevadas e na sobrevalorização cambial (praticada até 1998). Tais fatores, combinados com a liberalização comercial unilateral e o desmonte do modelo anterior de regulação da agricultura, provocaram efeitos drásticos sobre o setor agropecuário brasileiro. 0 volume de importações agrícolas disparou, alcançando patamar sem precedentes (Delgado, 2009: 20). 0 declínio acentuado dos preços impactou severamente a renda agrícola, principalmente na agricultura familiar.

No que tange à política fundiária, o programa do PSDB prescrevia medidas assistencialistas, tanto que o programa de reforma agrária estava vinculado ao Comunidade Solidária. ${ }^{3}$ Entretanto, a confluência de três fatores durante os anos de 1995-97 contribuiu para alterar 
sensivelmente a conjuntura agrária. O primeiro foi a repercussão nacional e internacional alcançada pela violência policial extrema contra trabalhadores rurais em Corumbiara (RO), em agosto de 1995, e principalmente em Eldorado dos Carajás (PA), em abril de 1996. Ambos os episódios resultaram em 28 trabalhadores mortos e alimentaram uma série de protestos no Brasil como no exterior contra a violência no campo e a favor da reforma agrária.

O segundo fator foi o aumento sensível dos conflitos agrários e das ocupações de terra em praticamente todo o país (CPT, 2003). No caso das ocupações, o MST era a força organizativa, mas em alguns estados sindicatos ligados à CONTAG também cumpriam esse papel (Leite e Medeiros, 2004). Em particular, no Pontal do Paranapanema - região caracterizada pela grilagem de terras públicas localizada no oeste do estado de São Paulo - diversas lideranças do MST foram presas e a tensão social aumentou com a violência da polícia e de grupos armados a serviço de latifundiários. Escrevendo no calor dos acontecimentos, Maria da Conceição Tavares captou o cerne do problema:

A reforma agrária não se destina a aplacar o potencial de conflito embutido na atual conjuntura do agro, mas sim a desfazer a condição objetiva de exclusão e marginalização da maioria da população rural produzida, sobretudo, nas últimas três décadas pelo processo de transformação capitalista acelerada da agricultura brasileira. (...) Este é o problema de fundo que revela a natureza estrutural do conflito atual, do qual a nossa sociedade infelizmente só se apercebe quando toma consciência das tensões dele resultantes, explicitadas na violência contra os trabalhadores do campo (Tavares, 1997: A3).

Outro fator decisivo foi a realização da "Marcha Nacional por Reforma Agrária, Emprego e Justiça". Organizada pelo MST, a marcha durou três meses e chegou à Brasília em 17 de abril de 1997, um ano depois do massacre em Eldorado dos Carajás. Apesar do descaso das autoridades e da campanha sistemática de desqualificação dos grandes meios de comunicação, a marcha, pacífica do início ao fim, conseguiu conquistar a simpatia de parte da opinião pública urbana. Aos "sem terra" se somaram, então, os "sem teto", os "sem emprego", entre outros, reunindo cerca de cem mil pessoas na primeira manifestação de massas contra as políticas neoliberais.

Tudo isso deu visibilidade às ocupações de terra e à bandeira da reforma agrária e projetou o MST (fundado em 1984) na cena política nacional e internacional. Àquela altura, já não era mais possível tratá-lo como simples "caso de polícia".

A resposta do governo federal veio logo após o massacre de Eldorado dos Carajás, com a criação do Ministério Extraordinário de Política Fundiária (MEPF). Raul Jungmann, designado para ocupar a nova pasta, assim se pronunciaria anos depois: 
O ministério só existe por conta do MST. Eu costumava dizer com um certo humor negro (...) que os meus constituintes foram os dezenove mortos em Eldorado de Carajás. Ou seja, quem me sentou [no Ministério] foram os caras que morreram lá (entrevistado em 27/11/2003).

O MEPF incorporou o INCRA, até então subordinado ao Ministério da Agricultura, espaço tradicional de articulação de interesses do patronato rural (Medeiros, 2002). A partir de então, o MEPF pôs em prática um conjunto de iniciativas, com o objetivo de aliviar as tensões no campo e restabelecer o protagonismo político do governo.

Em primeiro lugar, logo em 1996 encaminhou alterações no Imposto Territorial Rural (ITR), alegando que promoveria uma reforma agrária mediante tributação progressiva da terra. A iniciativa não foi para frente e a evasão fiscal continuou bastante elevada $(90 \%$ em 1997), mas se fez muita propaganda.

Em segundo lugar, em junho de 1997, uma série de medidas foi tomada no sentido de agilizar o processo de desapropriação, baratear as indenizações aos proprietários e acelerar o assentamento de famílias (MEPF, 1998). Nem todas foram aplicadas ou surtiram efeito relevante, mas buscou-se com isso recuperar a capacidade de resposta do governo à pressão social.

Em terceiro lugar, iniciou-se a desfederalização da reforma agrária, transferindo para estados e municípios a competência para conduzir os processos de obtenção de terras e assentamento (MEPF, 1997) e, assim, convertê-los em objetos de barganha negociados localmente. Tal política contrariava a posição de todas as organizações de trabalhadores rurais. Além disso, combinada com outras medidas, permitia a incorporação de entidades sindicais e excluía o MST da participação em algumas políticas públicas, fomentando a sua concorrência mútua (Leite e Medeiros, 2004).

Tais iniciativas se davam num contexto de repressão às lutas sociais no campo, mediante o acionamento da Polícia Federal para monitorar os sem terra, a realização de despejos de ocupantes de forma truculenta e ilegal e a prisão de lideranças. Até a extrema direita agrária voltou a se rearticular em algumas regiões, mobilizando instrumentos privados de violência, com frequência reforçados pela polícia e pelo Judiciário estaduais. Abertamente, entidades patronais pregavam o uso da força contra as ocupações (Carvalho Filho, 2001: 206).

Ao mesmo tempo, os principais veículos de comunicação passaram a disseminar uma imagem positiva do governo $\mathrm{FHC}$ em relação à reforma agrária e uma imagem negativa dos movimentos sociais, em particular do MST. Em geral, a mídia corporativa contrastava os dados oficiais que exaltavam o aumento do número de famílias assentadas, enquanto os sem terra e o MST eram associados a baderna, violência, corrupção e não vocação para a agricultura. 
De fato, como mostra a tabela 1, houve um aumento expressivo do número de famílias assentadas entre 1995 e 2002. Contudo - e sem entrar no mérito da precisão desses dados -, deve-se ressaltar que tais cifras resultaram não do planejamento e do compromisso governamental com a reforma agrária, mas sim da mobilização social de milhares de trabalhadores sem terra, da visibilidade dos conflitos agrários, da prática da ocupação como forma principal de pressão sobre os governos e da ação política dos movimentos sociais do campo.

Tabela 1. Famílias assentadas e área ocupada até 2002 - Brasil

\begin{tabular}{lrc}
\hline Ano & Familias assentadas & Área (hectares) \\
\hline Até 1994 & 58.317 & 16.290 .069 \\
\hline 1995 & 42.912 & 2.683 .062 \\
\hline 1996 & 62.044 & 2.515 .865 \\
1997 & 81.944 & 4.165 .754 \\
1998 & 101.094 & 3.025 .000 \\
\hline 1999 & 85.226 & 2.303 .118 \\
\hline 2000 & 60.521 & 2.151 .574 \\
2001 & 63.477 & 1.829 .428 \\
\hline 2002 & 43.486 & 2.401 .925 \\
\hline Total (governo FHC) & 540.704 & 21.075 .726 \\
\hline
\end{tabular}

Fonte: INCRA (atualizado em 31.08.2014).

\section{A INTRODUÇÃo DA REFORMA AGRÁria ASSISTIDA PELO MERCADO (RAAM) (1997-98)}

$\mathbf{U}$

m componente central da política agrária federal foi a implantação da reforma agrária assistida pelo mercado (market-assisted land reform) (Van Zyl et al., 1996). Propagada pelo Banco Mundial (BM), tal reforma prescrevia a concessão de financiamento para trabalhadores rurais pobres comprarem terras negociadas de maneira voluntária e direta com proprietários. Por essa transação patrimonial os proprietários seriam pagos previamente em dinheiro a preço de mercado, enquanto os compradores assumiriam os custos de aquisição da terra. Junto com o empréstimo, os compradores receberiam uma quantia variável de subsídio para investimentos em infraestrutura e produção. Esse mecanismo estimularia a barganha pelo imóvel, pois quanto menor fosse o preço da terra, mais recursos sobrariam para investimentos. Em outras palavras, a RAAM constituía uma operação de compra e venda de terras entre agentes privados financiada pelo Estado, acrescida de subsídio variável. Politicamente, 
tal modelo se inseriu nas estratégias de alívio da pobreza rural do BM complementares às políticas de ajuste macroeconômico (Burki e Perry, 1997).

0 discurso de legitimação da RAAM combinava dois argumentos: a afirmação da "oportunidade histórica" deflagrada pela redução do preço da terra e a desqualificação do "modelo tradicional" de reforma agrária, proclamado como esgotado ou falido.

0 primeiro argumento foi veiculado pelo governo, associando a queda relativa do preço da terra em algumas regiões com a perda de poder político dos grandes proprietários. Segundo Raul Jungmann: "O grande reformador agrário foi o Plano Real, que quebrou economicamente o latifúndio. Os movimentos sociais continuam dizendo que o latifúndio aqui tudo pode. Pode nada, o latifúndio foi derrotado" (entrevistado em 27/11/2003). Em 24 de março de 1999, no auge desse debate, o mesmo Jungmann, então ministro, afirmava em audiência pública na Comissão de Assuntos Sociais do Senado que "não podemos ficar cegos à realidade, que aponta, hoje, para uma queda enorme do preço da terra e a possibilidade da via negocial".

O segundo argumento consistia na afirmação de que a reforma agrária redistributiva havia falido historicamente, por ser um modelo discricionário, confiscatório, conflitivo e inviável politicamente em regimes democráticos ao se basear no instrumento da desapropriação e na indenização (quando existente) aos proprietários de terra por meio de TDAs. Além disso, tal modelo seria também centralizador, burocratizado, paternalista, ineficiente economicamente e ineficaz na redução da pobreza rural (cf. Van Zyl et al., 1996; Deininger e Binswanger, 1999; Teófilo, 2003). Milton Seligman, então presidente do INCRA, assim explicava em 1997 a posição do governo: "O pior negócio para o Governo Federal é a desapropriação litigiosa (...). Qual é o melhor negócio? É aquele indicado pelo mercado, em que conseguimos, de comum acordo, encerrar uma negociação em valores de mercado" (Senado, audiência pública na Comissão de Assuntos Econômicos, 04/09/1997).

As críticas do BM e do governo brasileiro à reforma agrária desapropriacionista se basearam na construção de um tipo ideal ao qual se atribuiu a responsabilidade pelo suposto fracasso da imensa maioria das reformas agrárias realizadas pelo mundo afora. Desse modo, pode-se dizer que tal crítica foi feita de maneira enviesada, desconsiderando a análise dos conflitos sociais que definiram a natureza, o grau, a extensão, o ritmo, a direção e mesmo o refluxo das reformas agrárias, sempre muito heterogêneas entre si. Tal crítica tinha o objetivo de disputar politicamente qual deveria ser o papel legítimo do Estado em sociedades altamente desiguais, marcadas por altos índices de concentração da propriedade da terra e tensões de classe no campo, numa fase específica do capitalismo neoliberal.

Para os técnicos do BM, o Brasil oferecia condições ideais para a RAAM, porque estava em curso uma política econômica que impactava regressivamente o tecido social rural, existia 
enorme demanda por terra e havia uma tendência de queda do preço dos imóveis rurais em algumas regiões. Por sua vez, pelo lado do governo, era preciso não apenas responder ao aumento da pressão social por terra, mas também pautar a maneira pela qual a questão agrária deveria ser processada política e institucionalmente. Essa convergência de interesses possibilitou a introdução da RAAM no Brasil.

Documentos do BM revelam claramente que o aumento dos conflitos agrários e das ocupações de terra foi crucial para a decisão do governo brasileiro de implementar a RAAM mediante empréstimo externo:

Cada vez mais, as ocupações de terras têm gerado uma pressão significativa sobre o governo brasileiro para que aja rapidamente sobre os problemas existentes na posse de terras (...) Para o governo brasileiro, a reforma agrária assistida pelo mercado proporciona uma oportunidade de responder às pressões dos trabalhadores sem terra de uma maneira menos conflituosa do que abordagens administrativas (BM, 1997e: 7).

O nexo entre ocupações de terra, conflitos agrários e desapropriação fica ainda mais claro em outro documento do BM e revela a intenção do governo FHC de priorizar a RAAM:

0 modelo de reforma agrária através da distribuição de terras pelo governo é um círculo vicioso: a terra é redistribuída onde há conflitos sociais e os conflitos sociais pressionam o programa de redistribuição de terras do governo (...) À medida que novas alternativas começam a fazer efeito [a RAAM], o governo poderá reduzir a ênfase nas desapropriações e consequentemente quebrar a ligação entre sua política de reforma agrária e os conflitos rurais (BM, 2003: 127).

0 primeiro projeto desse gênero começou em agosto de 1996 no estado do Ceará, durante o governo de Tasso Jereissati (PSDB), e recebeu o nome de "Reforma Agrária Solidária". O governo criou em 1996 um fundo estadual e nele aportou cerca de R\$ 4 milhões, acrescidos de um empréstimo do BM de R\$ 6 milhões. Financiou-se a compra de 44 imóveis por 694 famílias, totalizando 23.622 hectares. A iniciativa estimulou a elevação do preço da terra onde foi implantada (Brandão, 2000). Dessa pequena experiência nasceu o projeto-piloto Cédula da Terra (PCT), estendido para os outros quatro estados (BA, MA, PE e norte de MG) por meio de novo empréstimo aprovado pelo BM em abril de 1997 no valor de US\$ 90 milhões. O PCT financiaria a compra de terras por 15 mil famílias em 4 anos, mas esperava-se posteriormente financiar um milhão de famílias em até seis anos (BM, 1997). 0 projeto financiava a compra de qualquer imóvel rural, mesmo os passíveis de desapropriação.

O PCT foi criticado pelo MST como expressão do neoliberalismo no campo. Gilmar Mauro expôs em audiência pública no Senado a posição do movimento: 
Não me causa surpresa esse tipo de programa, porque, ao longo dos anos, verificamos uma série de iniciativas, todas elas periféricas (...) Assentar 15 mil num universo de 4,8 milhões de famílias [sem terra], qual é o impacto social desse programa? Nenhum impacto (...) No nosso entendimento, o Cédula da Terra é mais um, entre tantos outros, para confundir a população e não resolver o problema na essência (Senado, Comissão de Assuntos Econômicos, 04/09/1997).

Na mesma ocasião, embora fosse da Executiva Nacional do PSDB, Francisco Urbano, então presidente da CONTAG, fez uma crítica contundente tanto à política de reforma agrária como ao PCT. No primeiro caso, sustentou que:

O que se faz no Brasil é uma enganação da sociedade (...). Uma reforma agrária envolve uma decisão política de intervenção na estrutura agrária, criando um novo modelo de desenvolvimento, em que se desconcentra poder, riqueza e se estabelece um novo patamar do processo de desenvolvimento do país. 0 que se faz hoje é apagar fogo de um lado e de outro: desapropria-se um pedaço aqui pela ocupação, desapropria-se um outro pedaço ali porque o fazendeiro ofereceu. Não se muda nada da estrutura agrária da região (ibidem).

No segundo caso, embora ressaltasse que as federações sindicais estavam debatendo se deveriam ou não participar do PCT - sinalizando que não se tratava de uma questão resolvida dentro da CONTAG -, Francisco Urbano afirmou que:

O Cédula da Terra (...) não passa de um atraso - dos maiores que já vi - no processo de reforma agrária neste país. É nitidamente um retrocesso no processo da reforma agrária e uma forma de o Estado fugir do seu papel ao não intervir na mudança de sequer um patamar na estrutura agrária brasileira (ibidem).

O significado e a intencionalidade política do PCT naquela conjuntura foram diagnosticados pela própria avaliação contratada pelo governo e financiada pelo BM:

É possível dizer que, na atual conjuntura de mobilização, ao colocar nova opção de acesso à terra, o Cédula da Terra introduz uma disputa política e ideológica com outros movimentos sociais e seus mediadores (principalmente o MST, setores da Igreja Católica e da sociedade civil organizada em ONGs), os quais detêm, hoje, a iniciativa política neste campo e defendem 0 acesso à terra via instituto da desapropriação (Buainain et al, 1999: 281).

Antes mesmo de realizar a avaliação dos resultados do PCT - como previa o acordo de empréstimo com o BM -, o governo FHC mobilizou a sua base no Congresso Nacional para aprovar a criação do Banco da Terra. Acompanhe-se como se deu esse processo. 
No dia 26 de fevereiro de 1997 foi protocolado no Senado o projeto de lei $n^{\circ} 25$, de autoria de Esperidião Amin (PPB-SC), para a criação do Banco da Terra, com base na experiência de um fundo de terras criado em seu governo (1983-87), voltado para financiar a compra de imóveis rurais de até doze hectares em Santa Catarina. No Congresso, o discurso da base governista ora reivindicou o Banco da Terra como sequência do PCT - posição que o vinculava diretamente ao BM -, ora afirmou que seria tão-somente uma ampliação da experiência catarinense (Câmara dos Deputados, 1998: 400-1024).

Como se tratava de uma matéria objeto de legislação complementar, o projeto teve de seguir rito especial, o qual exige maioria absoluta no Congresso, i. e., no mínimo 41 senadores e 257 deputados. 0 projeto original foi aprovado no Senado em 4 de dezembro do mesmo ano, sem debate e por unanimidade (58 votos), fato quase inédito durante o governo FHC (Senado, Diário, 1997: 26.967-77). Remetido à Câmara, onde a oposição era mais organizada e tinha mais peso político, sabidamente o projeto encontraria resistência. Por isso, o Executivo agiu preventivamente e a votação se fez em regime de urgência.

Acompanhando o debate legislativo (Câmara dos Deputados, 1998: 832-1024), observa-se que a oposição liderada pelo PT fez uma série de críticas, especialmente contra: a) a possibilidade de compra de propriedades passíveis de desapropriação, o que concorreria com o programa de reforma agrária e "premiaria" o latifúndio que não cumpre com a sua função social, na medida em que o pagamento aos proprietários seria em dinheiro a preço de mercado; b) a autorização de sindicatos patronais como intermediários, e não as entidades de representação de trabalhadores; c) a introdução de um mecanismo de compra de terra num período de queda da rentabilidade agrícola e de endividamento dos agricultores familiares, o que contribuiria ainda mais para a inadimplência e a possível falência desse segmento; d) as condições não favoráveis de financiamento; e) a possibilidade de aquecimento do mercado fundiário por conta da disponibilidade de crédito, o que tenderia a elevar o preço da terra rural.

A liderança do PT e de outros partidos da oposição manifestou-se em favor da criação de um fundo de terras que financiasse apenas a compra de propriedades produtivas, i. e., não passíveis de desapropriação. Também a CONTAG e o MST se manifestaram contrariamente à forma como o projeto se apresentava, conforme relataram em plenário os deputados ligados àquelas organizações (Câmara dos Deputados, 1998: 909-910). Por outro lado, a base governista reconhecia como procedentes diversas críticas da oposição, admitindo que o projeto original tinha inconsistências e problemas, mas assumiu a posição de que os ajustes seriam feitos quando da regulamentação da lei. Assim, a base governista rejeitou todas as emendas apresentadas e derrubou a proposta do bloco oposicionista de adiamento da votação para maior debate, criando uma situação paradoxal: embora admitisse que havia necessidade de 
modificações no projeto, impedia concretamente as possibilidades de sua realização. Após apenas uma única sessão de debate e na presença do ministro Jungmann, o projeto foi aprovado no dia 21 de janeiro de 1998 por folgada maioria: 351 votos a favor, 83 contra e 3 abstenções, votação suficiente para aprovar uma emenda constitucional. ${ }^{4}$

Consumava-se, assim, o apoio decisivo do patronato rural à criação do Banco da Terra, através da votação em bloco da bancada ruralista, que atravessava todos os partidos da base política do governo. Em 2 de fevereiro de 1998 era criado o Banco da Terra, através da lei complementar $n^{\circ}$ 93/98. Já não se tratava mais de um projeto-piloto, restrito a cinco estados da Federação, mas sim de um fundo de caráter nacional previsto constitucionalmente para financiar a compra de terras a trabalhadores rurais. Através desse expediente, o princípio básico da RAAM - a transferência voluntária de terras via transação de mercado em detrimento da desapropriação - deixava de ser um objeto externo à política fundiária brasileira e passava a integrá-la por força de uma lei aprovada por maioria absoluta no Congresso Nacional.

0 governo federal fez uso de intensa propaganda para divulgar as supostas vantagens do novo modelo, ao mesmo tempo em que as ocupações de terra eram criminalizadas. Baseado na ideia de acesso "negociado" e "sem conflitos", o marketing foi direcionado tanto para o público mobilizado em ocupações e acampamentos como para o potencialmente mobilizável. Gilmar Mauro, dirigente do MST, resumiu da seguinte maneira a combinação entre repressão e propaganda:

Se você perguntar "quem quer terra?", obviamente que todo mundo levanta a mão. Agora, se você perguntar "quem quer ir para uma ocupação?", num contexto de repressão policial, a coisa muda completamente de figura, porque os trabalhadores estão assistindo à Globo todo dia e vendo nós apanharmos e sermos despejados. 0 povo faz análise de conjuntura (...) e pensa: "eu quero terra, mas desse jeito não!". Claro, não é idiota! Então, todo um contexto foi criado precisamente para tentar introduzir uma alternativa (...) para combater ideologicamente os movimentos sociais e a luta de classes (entrevistado em 13/11/2003).

\section{O SEGUNDO GOVERNO FHC (1999-2002)}

$\mathrm{O}$ segundo mandato de FHC se iniciou com a crise do Plano Real e a adoção de um programa de ajuste fiscal acordado com o Fundo Monetário Internacional (FMI). Quanto à política agrária, no primeiro semestre de 1999 o governo elaborou diretrizes que sistematizavam e aprofundavam as ações até então realizadas de modo relativamente disperso (MEPF, 1999a e 1999b). Tais diretrizes se concentravam em: a) descentralizar o programa de reforma 
agrária para estados e municípios; b) terceirizar e privatizar atividades e serviços técnicos vinculados aos assentamentos (como assistência técnica); c) titular os assentados em três anos, mediante a "emancipação" dos assentamentos em relação ao Estado, a fim de Ihes cobrar pelos custos da desapropriação; d) transferir para os assentados o ônus de diversas atribuições antes da competência do INCRA (como topografia, demarcação de lotes etc); e) manter o programa de reforma agrária como política de alívio da pobreza rural, sem pretensões de mudança estrutural; f) implantar a RAAM nacionalmente por meio do Banco da Terra.

Diante da repressão às lutas por terra e da implantação da RAAM, os movimentos de trabalhadores rurais buscaram construir maior unidade política no Fórum Nacional pela Reforma Agrária e Justiça no Campo. ${ }^{5}$ O Fórum encaminhou em outubro de 1998 um pedido de investigação ao Painel de Inspeção do $\mathrm{BM}^{6}{ }^{6}$ com uma série de críticas e denúncias contra o PCT. Em maio de 1999, o Painel (1999a) julgou improcedentes todos os argumentos do Fórum e não recomendou à diretoria do BM a investigação solicitada. 0 governo brasileiro usou tal recusa como prova da eficiência do projeto. Três meses depois, com base em documentos que continham inúmeras irregularidades e indícios de corrupção na gestão do PCT,7 o Fórum solicitou nova investigação, recebendo nova resposta negativa do Painel (1999b).

Foi então que a direção da CONTAG decidiu negociar com o BM e o governo federal a criação de um novo programa - o Crédito Fundiário de Combate à Pobreza Rural (CFCP), semelhante aos anteriores, porém com algumas modificações -, permitindo que o empréstimo de EUR 218,2 milhões, até então não aprovado pela diretoria do BM, fosse autorizado. Desse modo, o BM acabou não financiando o Banco da Terra, e sim o CFCP.

O BM havia tentado ganhar a adesão da CONTAG desde o início da implantação do PCT, embora até então desconsiderasse as reivindicações daquela entidade, que eram basicamente três: a) que o PCT fosse complementar à reforma agrária, e não concorrencial; b) que fosse dirigido a regiões de concentração de minifúndios ou onde não houvesse propriedades passíveis de desapropriação, numa lógica complementar à reforma agrária; c) que fosse um projeto concebido, executado e avaliado junto com os sindicatos, as federações sindicais e a CONTAG ${ }^{\text {. }}$. Por outro lado, embora tenha apoiado as duas solicitações ao Painel de Inspeção, a CONTAG nunca se recusou a negociar com o BM possíveis mudanças no PCT (Banco Mundial, 2000: 24).

A partir de então, a CONTAG continuou a vincular o PCT e o Banco da Terra à RAAM, mas passou a diferenciá-los do novo CFCP, considerando-o apenas um programa de "crédito fundiário" complementar à reforma agrária. Ao mesmo tempo, seguindo os termos da CONTAG, o CFCP ficou impedido de comprar áreas passíveis de desapropriação e criaram-se mecanismos de participação e cogestão por sindicatos de trabalhadores rurais. Com a criação do novo programa, a luta contra o PCT e o Banco da Terra se enfraqueceu e saiu da pauta do Fórum. 
Diversas avaliações mostraram a incapacidade da RAAM de promover o desenvolvimento econômico e a justiça social no campo no Brasil e em outros países, razão pela qual esse modelo não substitui uma reforma agrária redistributiva. ${ }^{9}$ Mesmo com melhorias técnicas que aperfeiçoassem programas desse gênero - aumentando, p. ex., mecanismos de participação e transparência por meio da mediação sindical -, tais medidas não seriam suficientes para superar os limites estruturais desse modelo, como a dependência da oferta de terras por parte de proprietários e a incapacidade de democratizar a estrutura fundiária e alcançar escala social, dado o pagamento prévio em dinheiro e a preço de mercado.

No biênio 2001-02, o governo FHC realizou ainda duas ações importantes. A primeira foi o cadastramento de solicitações de acesso à terra em agências dos Correios de todo país. Mediante intensa propaganda, a campanha prometia uma "reforma agrária sem conflitos". 0 número de pessoas cadastradas chegou a 839.715, mas nenhuma foi assentada. A segunda ação consistiu na proibição por dois anos de vistoria pelo INCRA de áreas ocupadas, o que inviabilizava os processos de desapropriação.

\section{CONCLUSÃO}

e a CF 1988 ampliou a esfera de direitos de cidadania no Brasil, no capítulo da política fun-
diária o resultado ficou aquém das expectativas e reivindicações dos movimentos populares que surgiram no bojo da crise da ditadura. No período examinado, a fiscalização pelo Estado da obrigatoriedade de cumprimento da função social da propriedade se restringiu, quando e onde ocorreu, ao critério econômico, e mesmo assim com inúmeras limitações e ambiguidades, deixando de lado os critérios ambiental e trabalhista. Ao mesmo tempo, nos casos de desapropriação para fins de reforma agrária, consolidou-se a tendência de remuneração dos proprietários com base em valores de mercado (ou acima de), onerando imensamente os cofres públicos. Por tudo isso, a correlação de forças plasmada na CF 1988 e na legislação posterior bloqueou a realização de uma reforma agrária estrutural e massiva no Brasil, permitindo, no máximo, políticas de assentamentos sujeitas a vicissitudes de ordem política, orçamentária e operacional.

A introdução do neoliberalismo no Brasil se deu com o governo Collor, que tratou as lutas populares no campo por meio de repressão e criminalização. Não houve nenhuma desapropriação para fins de reforma agrária, e o governo buscou estimular outros instrumentos de obtenção de terras segundo a lógica mercantil, como a criação de bolsas de arrendamento.

Já o governo Itamar fez uma inflexão no tratamento dos movimentos sociais do campo e pôs em prática um programa modesto de assentamentos, cuja execução foi limitada por pressões internas e externas ao governo e pela prioridade atribuída à implantação do Plano Real. 
À frente de um programa radical de estabilização e reestruturação econômica que combinava o uso da taxa de câmbio como instrumento de combate inflacionário, a abertura comercial, a desregulação financeira, a desindexação da economia, o ajuste fiscal e a privatização de empresas públicas, o governo FHC pôs em prática o fortalecimento do mercado em detrimento do Estado - ainda que à custa e por meio do próprio Estado -, com efeitos drásticos sobre a maioria da população rural do país. Nesse contexto, a política de reforma agrária foi encarada como medida de alívio da pobreza rural, sem qualquer pretensão de democratização da estrutura fundiária do país. Porém a alta visibilidade da violência no campo contra trabalhadores rurais, o volume crescente de conflitos agrários e ocupações de terra e a gravitação de movimentos sociais como o MST recolocaram na agenda política nacional os temas da reforma agrária e da justiça social no campo.

Para reverter a perda de protagonismo frente a fatos políticos produzidos à sua revelia, 0 governo FHC tomou uma série de medidas. De modo geral, elas apontaram para a internalização de mecanismos de mercado no programa de reforma agrária. Era o caso, por exemplo, da "emancipação" dos assentamentos rurais e da privatização de serviços de assistência técnica. Porém a principal iniciativa posta em prática consistiu na implantação da RAAM. Para fazê-lo, o governo FHC criminalizou as ocupações de terra e desqualificou as ações dos movimentos sociais, com 0 suporte dos grandes veículos de comunicação. Por isso, é correto afirmar que a execução da RAAM andou lado a lado com a coerção estatal e a difusão da ideologia do acesso à terra "sem conflito" . No auge da polarização com o MST, uma campanha publicitária oficial dizia: "para que pular a cerca se a porteira está aberta", aludindo à possibilidade de obtenção de terra via mercado.

As críticas do BM e do governo brasileiro à reforma agrária desapropriacionista simplesmente naturalizavam a deformação política e juridicamente construída do aparato estatal voltado para a democratização da propriedade da terra. Exemplo disso é o que ocorreu com os TDAs: criados para dar escala à reforma agrária, foram convertidos em moeda de alta liquidez transacionável no mercado financeiro, elevando a dívida fundiária da União e transformando o Estado no agente de remuneração da renda da terra. Portanto, como, no Brasil, sustentar a tese de falência do "modelo desapropriacionista", se ele nunca foi levado adiante de maneira adequada?

A implantação da RAAM condensou as principais contradições políticas entre o governo FHC e as organizações aglutinadas no Fórum Nacional pela Reforma Agrária e Justiça no Campo. O Fórum levou adiante diversas iniciativas inovadoras no plano nacional e internacional para impedir o empréstimo do BM que permitiria ao governo brasileiro contar com uma fonte externa de financiamento para o Banco da Terra em todo o país. Todavia, da negociação da CONTAG com o governo federal e o BM surgiu o CFCP, dando sequência à experiência dos programas anteriores, porém com novidades importantes, como a proibição de compra de 
áreas passíveis de desapropriação e a cogestão por sindicatos de trabalhadores rurais. Para a CONTAG, o CFCP representou a possibilidade de viabilizar uma demanda mais antiga de setores do movimento sindical, embora até então secundária na pauta da entidade e trazida à tona num momento político adverso aos movimentos sociais do campo.

Para o BM, a experiência brasileira com a RAAM foi crucial, por se tratar do maior país da América Latina, com forte ativismo social no meio rural e, historicamente, um dos cinco maiores clientes da instituição. Nenhum outro país contratou tal volume de empréstimos junto ao BM para essa finalidade. Ao empurrar a RAAM para o governo brasileiro, o BM não fez nada que não estivesse de acordo com as perspectivas políticas, preferências e convicções dos altos mandos de Brasília naquele período.

\section{Notas}

1 Essa tendência se agravou após 1995, quando os TDAs foram aceitos como meio de pagamento nos processos de privatização de empresas públicas, convertendo-se em moeda paralela e ativo financeiro com boa liquidez. Cf. Delgado (2012).

2 Ganhara visibilidade nacional a campanha conduzida pelo sociólogo Herbert de Souza, o Betinho, contra a fome e miséria no país.

3 Criado em 1995 e encerrado em 2002, tratava-se de um programa ligado à Casa Civil da Presidência da República com o objetivo de coordenar as ações governamentais voltadas para o combate à fome e à pobreza. Previa a colaboração entre órgãos públicos, entidades privadas e organizações não governamentais.

4 Votaram a favor deputados dos seguintes partidos: PSDB, PFL, PMDB, PTB, PPB, PL, PP, PPS e um deputado do PDT. Os votos contrários vieram do PT, PSB, PCdoB, PSTU, um do PMDB e outro do PDT. O PV se absteve.

50 Fórum foi criado em 1995 e congregava àquela altura mais de 30 organizações, entre as quais MST e CONTAG.

60 Painel de Inspeção foi criado em 1994 como instância independente para receber reclamações de indivíduos e grupos que se sentiam prejudicados pela realização de projetos financiados pelo BM. A reclamação deve demonstrar que os efeitos negativos decorrem da não observância das normas e procedimentos do BM na elaboração, execução e avaliação dos projetos financiados. A criação do Painel foi uma resposta limitada a críticas de grupos ambientalistas e ligados à defesa dos direitos humanos.

7 Como o governo brasileiro não liberava informações sobre a implementação do PCT, o Fórum acionou dois parlamentares do PT, que assinaram requerimento oficial de informações ao MEPF em 2 de março de 1999. Dois meses depois, numerosa documentação foi entregue aos parlamentares e imediatamente repassada ao Fórum. Tal documentação não foi apresentada pelo governo federal ao Painel de Inspeção, nem foi considerada na resposta do BM (Fórum, 1999).

8 Conforme depoimento de Francisco Urbano na Comissão de Assuntos Econômicos do Senado em 4 de setembro de 1997.

9 A revista Third World Quarterly fez uma edição especial (v. 28, n. 8) sobre o tema em 2007 com diversos estudos nacionais. 


\section{REFERÊNCIAS BIBLIOGRÁFICAS}

BANCO MUNDIAL. Project Appraisal Document to Brazil for Land Reform and Poverty Alleviation Pilot Project. Washington, DC: Report n 16342-BR, 1997

Project Appraisal Document to Brazil for Land-Based Poverty Alleviation Project I. Report n 19585, 2000.

Rural Poverty Alleviation in Brazil: Toward an Integrated Strategy. Washington, DC, 2003.

BARRACLOUGH, Sólon. A reforma agrária nos países em desenvolvimento: o papel do Estado e de outros agentes. In: TEÓFILO, Edson (org.) A economia da reforma agrária: evidências internacionais. Brasília: MDA/ CNDRS/NEAD, 2001.

BUAINAIN, Antônio M. et al. Relatório preliminar de avaliação do Projeto Cédula da Terra. Brasília: UNICAMP/ NEAD/MEPF, junho, 1999.

BURKI, Shahid Javed; PERRY, Guillermo. The Long March: A Reform Agenda for Latin America and the Caribbean in the Next Decade. Washington, DC: The World Bank, 1997.

CÂMARA DOS DEPUTADOS. Notas taquigráficas da sessão ordinária 012.6.50.E de 21 de janeiro, 1998.

CARVALHO Filho, José Juliano de. Política agrária do governo FHC: desenvolvimento rural e a Nova Reforma Agrária. In: LEITE, Sérgio (org.) Políticas públicas e agricultura no Brasil. Porto Alegre: EDUFRGS, 2001.

CPT. Conflitos no campo Brasil. Goiânia: Comissão Pastoral da Terra, 2003.

DAGNINO, Evelina. Construção democrática, neoliberalismo e participação: os dilemas da confluência perversa. Política \& Sociedade, v. 3, n. 5, pp. 139-164.

DEININGER, Klaus; BINSWANGER, Hans. The Evolution of the World Bank's Land Policy: Principles, Experience and Future Challenges. The World Bank Research Observer, vol. 14, n.2, 1999, pp. 247-276.

DELGADO, Guilherme. Do capital financeiro na agricultura à economia do agronegócio: mudanças cíclicas em meio século (1965-2012). Porto Alegre: Ed. UFRGS, 2012.

DELGADO, Nelson G. Papel e lugar do rural no desenvolvimento nacional. Rio de Janeiro: IICA/MDA, 2009.

DREIFUSS, René. O jogo da direita na Nova República. Petrópolis: Vozes, 1989.

FACHIN, Luiz Edson. Depois da Lei Agrária: o que muda no campo brasileiro? Democracia na terra, n. 10, 1993, pp. 15-30.

FERREIRA, Brancolina et al. Constituição vinte anos: caminhos e descaminhos da reforma agrária - embates (permanentes), avanços (poucos) e derrotas (muitas). Acompanhamento e Análise de Políticas Sociais (IPEA), n 17, vol. 2, 2009.

FÓRUM NACIONAL PELA REFORMA AGRÁRIA E JUSTIÇA NO CAMPO. Segunda solicitação ao Painel de Inspeção. Brasília, 27 de agosto de 1999.

GOMES DA SILVA, José. Buraco negro: a reforma agrária na Constituinte. São Paulo: Paz e Terra, 1989.

A reforma agrária na virada do milênio. Campinas: ABRA, 1996.

LEITE, Sérgio; MEDEIROS, Leonilde. Marchas e contra-marchas na política agrária no governo Fernando Henrique Cardoso (1995-2002). In: INESC (org.) A era FHC e o governo Lula: transição? Brasília: INESC, 2004. 
MEDEIROS, Leonilde. Movimentos sociais, disputas políticas e reforma agrária de mercado no Brasil. Rio de Janeiro: CPDA/UFRRJ e UNRISD, 2002.

MEPF. Diretrizes do processo de descentralização da reforma agrária. Brasília, 1997.

Mudanças legais que melhoraram e apressaram as ações da reforma agrária. Brasília, 1998.

Agricultura familiar, reforma agrária e desenvolvimento local para um novo mundo rural. Brasília, 1999a.

A nova reforma agrária. Brasília, 1999b.

PAINEL DE INSPEÇÃO. Report and Recommendation on Request for Inspection - Brazil: Land Reform and Poverty Alleviation Pilot Project. Washington, DC, May, 1999a.

Report and Recommendation on Second Request for Inspection - Brazil: Land Reform and Poverty Alleviation Pilot Project. Washington, DC, December, 1999b.

SENADO FEDERAL. Notas taquigráficas da audiência pública na Comissão de Assuntos Econômicos em 4 de setembro de 1997.

Notas taquigráficas da audiência pública na Comissão de Assuntos Sociais em 24 de março de 1999.

STÉDILE, João Pedro e FERNANDES, Bernardo M. Brava gente: a trajetória do MST e a luta pela terra no Brasil. São Paulo: Editora Fundação Perseu Abramo, 1999.

TAVARES, Maria da Conceição. A questão agrária. Folha de São Paulo, 27/04/1997.

TEÓFILO, Edson. Brasil: nuevos paradigmas de la reforma agraria. In: TEJO, Pedro (org.) Mercados de tierras agrícolas en América Latina y el Caribe: una realidad incompleta. Santiago do Chile: Nações Unidas/CEPAL/ GTZ, vol. 1, 2003.

VAN ZYL, Johan et al. (eds) Agricultural Land Reform in South Africa: Policies, Markets and Mechanisms. Cape Town: Oxford University Press, 1996.

\section{ENTREVISTAS REALIZADAS}

Gilmar Mauro - membro da direção nacional do MST (em São Paulo no dia 13/11/2003).

Raul Jungmann - ministro do Desenvolvimento Agrário (1997-2002), deputado federal (PPS/PE) entre 2003-06 (em Brasília no dia 27/11/2003). 